\title{
Genetic diversity of European pear cultivars (Pyrus communis L.) and wild pear (Pyrus pyraster (L.) Burgsd.) inferred from microsatellite markers analysis
}

\author{
Lukasz Wolko • Wojciech Antkowiak • \\ Elżbieta Lenartowicz · Jan Bocianowski
}

Received: 17 February 2010/Accepted: 10 June 2010/Published online: 1 July 2010

(C) The Author(s) 2010. This article is published with open access at Springerlink.com

\begin{abstract}
The aim of this study was to identify the group of highly polymorphic microsatellite markers for the identification of six pear cultivars (P. сотmunis) and two individuals of wild pear (P. pyraster). From among 40 tested SSR markers, 19 were selected to profile genetic diversity in pear genotypes due to high polymorphisms. These markers showed high heterozygosity levels (0.5-1) and, on average, 6.4 alleles per marker were found. The set of microsatellite markers employed in this study demonstrated usefulness of microsatellite markers for the identification of pear genotypes. The examined wild forms were represented in this study by only two individuals of $P$. pyraster. It can be assumed that these forms were distinctly different from the cultivated pear cultivars.
\end{abstract}

Keywords Microsatellite Pyrus communis . Pyrus pyraster $\cdot$ SSR markers

Ł. Wolko $(\bowtie) \cdot$ E. Lenartowicz

Department of Biochemistry and Biotechnology, Poznań University of Life Sciences, Wołyńska 35, 60-637 Poznań, Poland

e-mail:wolko@o2.pl

W. Antkowiak

Department of Botany, Poznań University of Life

Sciences, Wojska Polskiego 71c, 60-625 Poznań, Poland

J. Bocianowski

Department of Mathematical and Statistical Methods, Poznań University of Life Sciences, Wojska Polskiego 28, 60-637 Poznań, Poland

\section{Introduction}

SSRs (simple sequence repeats, also designated as microsatellites) have become genetic markers of choice in many plant species due to their abundance, high degree of polymorphism and suitability for automation (Weber and May 1989). SSR markers have several advantages over other molecular markers which ensure a more reliable method for DNA fingerprinting. Among others, they exhibit codominant type of inheritance, a large number of alleles per locus and are abundant in genomes. Due to the fact that the use of SSRs is based on the polymerase chain reaction (PCR) method, the technique is simple and only a small amount of DNA is required.

The limited number of SSR primer pairs from European pear have been reported to date as most work in this field has focused on Japanese pear (Bao et al. 2007; Fernandez-Fernandez et al. 2006; Yamamoto et al. 2001; Yamamoto et al. 2002a, b, c). Although approximately $75 \%$ of the SSRs developed in $P$. pyrifolia are polymorphic in European pear, there is a need for more codominant markers for Pyrus (Yamamoto et al. 2002a, b, c).

The pear (Pyrus spp.) is one of the most important fruit trees, having been cultivated in Europe and Asia for at least 2-3 thousand years and is presently commercially grown in all temperate regions encompassing more than 50 countries of the world. Only one pear species occurs in Poland naturally, namely Pyrus pyraster (L.) Burgsd. (= Pyrus communis ssp. pyraster 
L.)-a pear which grows in wild conditions and is widely known as common or field pear. $P$. pyraster species comes from areas of western Black Sea regions, but distribution of this species extend from the British Isles to Latvia (Browicz 1982, Meusel et al. 1965, Paganova 1996, 2001, 2003a, b, c, 2009, Stephan et al. 2003, Terpo and Franco 1968).

The term Pyrus communis L. (= P. domestica Med.) is generally used to refer to pear trees grown in orchards. Apart from them, however, a hybrid Pyrus $\times$ amphigenea Domin ex Dostálek also occurs which develops as a result of crossing of wild pears with cultivated varieties. In addition, a limited number of representatives of foreign origin can be found, although these are planted primarily in parks and gardens (Dostalek 1989).

It is quite difficult to give an accurate number of pear species in the world because they cross easily with one another and the obtained crosses are allocated various taxonomic positions. Terpo (1985), for example, mentions 52 pear species, while Browicz (1993) gives a list of 38 species and, additionally, 33 examples of interspecific Pyrus hybrids as well as 4 examples of intergeneric crosses of Pyrus genus with Sorbus, Cydonia and Malus. Bell (1986) mentions seven other instances of interspecific Pyrus hybrids. Kutzelnigg and Silbereisen (1995) maintain that the genus comprises from 20 to 74 species, depending on the type of the adopted approach, all indigenous to Europe, Asia, and the mountainous regions of North Africa.

Pear genetic resources have not been fully identified due to its low morphological diversity, lack of differentiating characters among species and widespread crossability. Therefore, estimation of genetic diversity among Pyrus sp. is often very difficult.

\section{Materials and methods}

Six pear cultivars ( $P$. communis) were used in this study ('Conference', 'Red Williams', 'Amfora', 'Dicolor', 'Radana', 'Carola'). Every cultivar were represented by two individual trees. All the above cultivars were obtained from the Agro-Horticultural Experimental Farm in Przybroda. Leaves of two wild pear ( $P$. pyraster) specimens were collected in the region of Wierzonka (near Poznan). Genomic DNA was extracted from $2 \mathrm{~g}$ fresh leaf material following a modified cetyltrimethyl ammonium bromide (CTAB) protocol (Torres et al. 1993). 40 SSR primer pairs were obtained from Fernandez-Fernandez et al. (2006) and Yamamoto et al. (2002a, b). Primer sequences were verified with sequences deposited in the GenBank database (http://www.ncbi.nlm.nih.gov/Genbank/index. html). Microsatellite amplification was conducted using $2 \times$ PCR Master Mix (Fermentas Life Sciences, Canada) [Components: Taq DNA polymerase 0.5 units $/ \mu$, $\mathrm{MgCl}_{2} 4 \mathrm{mM}$ and dNTP $0.4 \mathrm{mM}$ ]. About $50 \mathrm{ng}$ of genomic DNA was mixed with $10 \mathrm{ng}$ of each primer (forward primer labelled with fluorescent chemical FAM) (Table 1), $1 \times$ PCR Master Mix and distilled water to make the final volume of $20 \mu \mathrm{l}$. Amplification was performed with 35 cycles at $94^{\circ} \mathrm{C}$ for $1 \mathrm{~min}$, $42-55^{\circ} \mathrm{C}$ for $1 \mathrm{~min}$ and $72^{\circ} \mathrm{C}$ for $2 \mathrm{~min}$., for denaturation, annealing and primer extension, respectively. The PCR products were separated and detected using a MegaBACE 1000 (GE Healthcare Life Sciences, USA) sequencer. The size of the amplified bands was determined based on an internal standard DNA (MegaBACE ET550-R Size Standard) with MegaBACE Fragment Profiler Version 1.2 (GE Healthcare).

For the diversity estimation of 19 SSR loci, the polymorphism information content (PIC), observed (HETo) and expected (HETe) heterozygosity and Simpson's Index of Diversity (SID) were calculated as proposed by Gourraud et al. (2005) and Simpson (1949). The coefficient of genetic similarity of the investigated cultivars was calculated using the following formula: $S_{i j}=N_{i j} / N$, where $S_{i j}$ is the genetic similarity between cultivars $i$ and $j, N_{i j}$-the number of alleles present at $i$-th and $j$-th cultivars, $N$-the number of all alleles, $i, j=1,2, \ldots, 8$. Cluster analysis was performed on the basis of the matrix of genetic similarity coefficients. The unweighted pair group method of arithmetic means (UPGMA) was used for clustering by the method of Nei and Kumar (Nei and Kumar 2000) employing for this purpose GenStat v. 7.1 software (Payne et al. 2003). Results of the performed grouping are presented in the form of a dendrogram.

\section{Results}

From among 40 tested SSR markers, 19 were selected to profile the genetic diversity among the pear genotypes due to high polymorphisms in the tested pear cultivars and wild pear germplasm (Fernandez-Fernandez et al. 
Table 1 SSR genotypes of $P$. pyraster and pear cultivars

\begin{tabular}{lllllllll}
\hline Marker & $P$. pyraster 1 & $P$. pyraster 2 & 'Conference' & 'Red Williams' & 'Amfora' & 'Radana' & 'Dicolor' & 'Carola' \\
\hline EMPc10 & {$[183][183]$} & {$[157][172]$} & {$[155][157]$} & {$[155][185]$} & {$[157][172]$} & {$[155][172]$} & {$[157][185]$} & {$[157][172]$} \\
EMPc102 & {$[176][179]$} & {$[160][179]$} & {$[172][184]$} & {$[182][184]$} & {$[172][184]$} & {$[182][184]$} & {$[166][184]$} & {$[164][184]$} \\
EMPc104 & {$[94][96]$} & {$[94][108]$} & {$[94][114]$} & {$[94][96]$} & {$[94][114]$} & {$[94][114]$} & {$[94][98]$} & {$[96][114]$} \\
EMPc105 & {$[166][168]$} & {$[146][149]$} & $[178] 180]$ & {$[156][190]$} & $[178] 180]$ & {$[176][178]$} & {$[154][156]$} & {$[162][166]$} \\
EMPc106 & {$[208][208]$} & {$[104][179]$} & {$[196][218]$} & {$[114][118]$} & {$[218][222]$} & {$[104][179]$} & {$[104][118]$} & {$[114][116]$} \\
EMPc110 & {$[160][160]$} & {$[160][160]$} & {$[160][200]$} & {$[160][200]$} & {$[180][200]$} & {$[178][180]$} & {$[160][168]$} & {$[160][180]$} \\
EMPc111 & {$[97][99]$} & {$[99][104]$} & {$[94][99]$} & {$[97][99]$} & {$[94][99]$} & {$[97][99]$} & {$[94][97]$} & {$[97][99]$} \\
EMPc114 & {$[133][141]$} & {$[139][139]$} & {$[139][155]$} & {$[165][167]$} & {$[137][155]$} & {$[137][148]$} & {$[165][167]$} & {$[141][155]$} \\
EMPc115 & {$[170][172]$} & {$[172][183]$} & {$[178][188]$} & {$[165][188]$} & {$[172][188]$} & {$[176][180]$} & {$[176][188]$} & {$[176][186]$} \\
EMPc117 & {$[121][123]$} & {$[111][113]$} & {$[119][121]$} & {$[115][117]$} & {$[119][121]$} & {$[115][117]$} & {$[115][117]$} & {$[117][119]$} \\
KA14 & {$[180][188]$} & {$[188][188]$} & {$[188][190]$} & {$[180][188]$} & {$[188][190]$} & {$[180][188]$} & {$[180][188]$} & {$[188][188]$} \\
KU10 & {$[253][253]$} & {$[253][253]$} & {$[217][253]$} & {$[251][253]$} & {$[225][253]$} & {$[253][253]$} & {$[245][253]$} & {$[253][253]$} \\
BGT23b & {$[197][210]$} & {$[210][214]$} & {$[199][208]$} & {$[199][208]$} & {$[196][199]$} & {$[210][214]$} & {$[199][208]$} & {$[176][197]$} \\
NB105a & {$[140][154]$} & {$[140][156]$} & {$[142][170]$} & {$[156][174]$} & {$[142][178]$} & {$[142][174]$} & {$[156][174]$} & {$[156][174]$} \\
NB109a & {$[158][175]$} & {$[160][193]$} & {$[147][179]$} & {$[147][187]$} & {$[147][153]$} & {$[153][157]$} & {$[181][187]$} & {$[147][187]$} \\
NB113a & {$[152][154]$} & {$[158][160]$} & {$[146][150]$} & {$[150][154]$} & {$[138][150]$} & {$[152][154]$} & {$[152][154]$} & {$[150][154]$} \\
NH025a & {$[75][89]$} & {$[79][89]$} & {$[95][98]$} & {$[70][98]$} & {$[70][98]$} & {$[70][114]$} & {$[80][98]$} & {$[94][98]$} \\
NH027a & {$[138][146]$} & {$[146][160]$} & {$[132][156]$} & {$[126][158]$} & {$[132][156]$} & {$[132][156]$} & {$[134][158]$} & {$[156][156]$} \\
NB141b & {$[102][104]$} & {$[82][140]$} & {$[104][132]$} & {$[82][94]$} & {$[102][104]$} & {$[104][132]$} & {$[94][104]$} & {$[102][104]$} \\
\hline
\end{tabular}

2006: EMPc10, EMPc102, EMPc104, EMPc105, EMPc106, EMPc110, EMPc111, EMPc114, EMPc115, EMPc117; Yamamoto et al. 2002a: KA14, KU10, BGT23b; Yamamoto et al. 2002b: NB105a, NB109a, NB112a, NH025a, NH027a, NB141b) Genotyping results enable to identify 32 unique alleles for $P$. pyraster genotypes and 31 unique alleles in six pear cultivars genomes. This result reflects diversity between two pear genotypes (Table 1). Polymorphism varied considerably; specific alleles per locus ranged between 3 and 11 (Table 2). As expected, the range of sizes amplified by each primer pair across different cultivars was considerable (20 bp in EMPc111 up to 120 bp size range in EMPc106). The observed heterozygosity (0.5-1), expected heterozygosity (0.45-0.95), polymorphism information content (PIC) (0.42-0.89) and Simpson's Index of Diversity (SID) (0.45-0.95) values were calculated (Table 2). These calculations indicated that these primers provide useful tools for fingerprinting, sample identification and studying the diversity of Pyrus germplasm and, also, for linkage mapping and marker-assisted selection.

The cluster analysis clearly identified the genetic relationship between pear genotypes and demonstrated the potential and ability of microsatellite markers for genome analysis (Fig. 1 and Table 3) The genetic tree divides into two main clusters. The first cluster groups all pear cultivars and the second one contains forms of wild pear. The highest genetic relationships were observed between cultivars 'Conference' and 'Amfora' as well as between 'Red Williams' and 'Dicolor'. The above results confirm the origin of these cultivars, because 'Amphora' was created by crossing 'Conference' with a Czech cultivar 'Holenicka'; 'Dicolor' derived from cross-breeds of 'Red Williams' and the same 'Holenicka' cultivar (Rejman 1994). It is possible to partially reconstruct the 'Holenicka' genotype by analyzing genotypes of these four cultivars (both alleles for 9 loci and one for 7 loci).

\section{Discussion}

The microsatellite markers were able to distinguish between studied pear genotypes. The high degree of polymorphism of microsatellite markers allowed a rapid and efficient identification of pear cultivars. The high polymorphism information content (PIC) value of microsatellite markers (with the average of over 0.62) makes them an ideal tool for differentiating 
Table 2 Locus information relating to 19 loci SSR, where $k$ is the number of individuals in which the locus was amplified, $n$ is the number of alleles, $g$ is the number of unique genotypes, $p$ is the frequency of the most prevalent genotype, HETo is observed heterozygosity, HETe is expected heterozygosity and SID is Simpson's Index of Diversity

\begin{tabular}{|c|c|c|c|c|c|c|c|c|c|}
\hline Marker & $\mathrm{k}$ & $n$ & $\mathrm{~g}$ & $p$ & HETo & HETe & PIC & SID & Range of allele size \\
\hline EMPc10 & 8 & 5 & 6 & 0.375 & 0.875 & 0.825 & 0.753 & 0.825 & $150-190$ \\
\hline EMPc102 & 8 & 8 & 6 & 0.250 & 1.000 & 0.850 & 0.792 & 0.850 & $150-190$ \\
\hline EMPc104 & 8 & 5 & 5 & 0.375 & 1.000 & 0.750 & 0.689 & 0.750 & $90-120$ \\
\hline EMPc105 & 8 & 11 & 7 & 0.250 & 1.000 & 0.950 & 0.889 & 0.950 & $145-190$ \\
\hline EMPc106 & 8 & 9 & 7 & 0.250 & 0.875 & 0.933 & 0.873 & 0.933 & $100-220$ \\
\hline EMPc110 & 8 & 5 & 6 & 0.250 & 0.750 & 0.717 & 0.670 & 0.717 & $155-210$ \\
\hline EMPc111 & 8 & 4 & 4 & 0.500 & 1.000 & 0.717 & 0.626 & 0.717 & $90-110$ \\
\hline EMPc114 & 8 & 8 & 7 & 0.250 & 0.875 & 0.917 & 0.855 & 0.917 & $125-170$ \\
\hline EMPc115 & 8 & 9 & 8 & 0.125 & 0.875 & 0.900 & 0.840 & 0.900 & $165-200$ \\
\hline EMPc117 & 8 & 7 & 5 & 0.375 & 1.000 & 0.875 & 0.808 & 0.875 & $105-130$ \\
\hline KA14 & 8 & 3 & 3 & 0.500 & 0.750 & 0.567 & 0.470 & 0.567 & $170-205$ \\
\hline KU10 & 8 & 5 & 5 & 0.500 & 0.500 & 0.450 & 0.420 & 0.450 & $210-260$ \\
\hline BGT23b & 8 & 8 & 5 & 0.375 & 1.000 & 0.883 & 0.818 & 0.883 & $170-220$ \\
\hline NB105a & 8 & 7 & 6 & 0.375 & 1.000 & 0.867 & 0.809 & 0.867 & $130-190$ \\
\hline NB109a & 8 & 10 & 7 & 0.250 & 1.000 & 0.917 & 0.857 & 0.917 & $135-210$ \\
\hline NB113a & 8 & 7 & 5 & 0.375 & 1.000 & 0.842 & 0.776 & 0.842 & $130-165$ \\
\hline NH025a & 8 & 9 & 7 & 0.250 & 1.000 & 0.883 & 0.826 & 0.883 & $60-120$ \\
\hline NH027a & 8 & 8 & 6 & 0.375 & 0.875 & 0.875 & 0.813 & 0.875 & $125-170$ \\
\hline NB141b & 8 & 6 & 5 & 0.375 & 1.000 & 0.825 & 0.757 & 0.825 & $75-140$ \\
\hline
\end{tabular}

between Pyrus genotypes. Similarly, high values of polymorphism were reported by other authors (Struss and Plieske 1998; Yamamoto et al. 2002a, b, c).

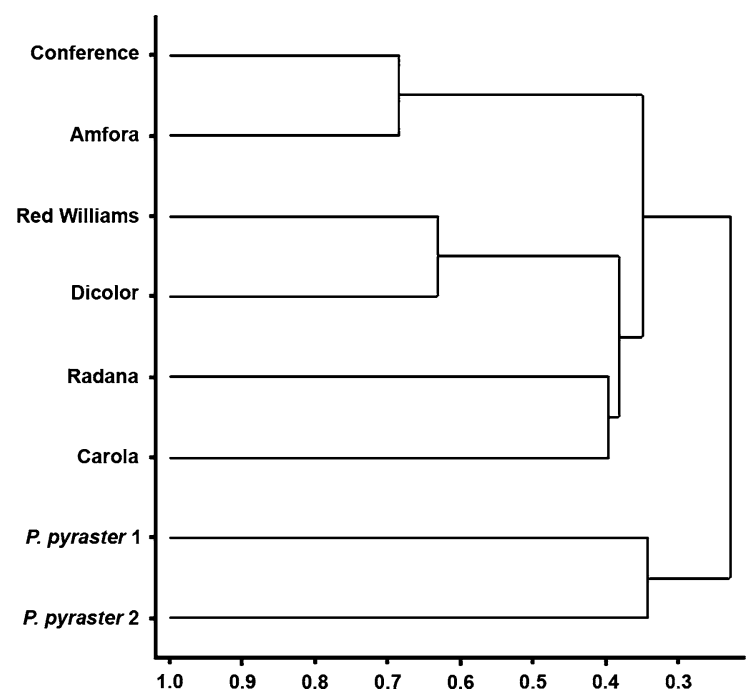

Fig. 1 UPGMA dendrogram describing genetic similarity of the examined cultivars
More heterozygotes than expected means excess outbreeding in the studied population and suggests the same kind of disassortative mating. The example of this form of disassortative selection is selfincompatibility (SI) in plants (mechanism described and observed in Pyrus species (Kim et al. 2002, 2006; Zisovich et al. 2004). Self-incompatibility is a genetic system that prevents self-fertilization through the recognition and rejection of pollen expressing the same allelic specificity as that expressed in the pistils (Castric and Vekemans 2004; Ma and Oliveira 2002). A key to understanding this variation is to investigate the evolutionary properties of the genes controlling in self-incompatybility plant mating systems. Selfincompatibility prevents inbred in wild pear populations and generates observed high level of variations.

The examined Pyrus wild forms were represented in this study by only two individuals of $P$. pyraster. It can be assumed that these forms were distinctly different from the pear cultivars. Our intention was to provide a molecular tool to identify and characterize Pyrus varieties and species estimating the genetic diversity. The set of microsatellite markers employed in this 
Table 3 Coefficients of genetic similarity of the studied cultivars

\begin{tabular}{llllllll}
\hline Similarity & $P$ pyraster 1 & $P$. pyraster 2 & 'Conference' & 'Red Williams' & 'Amfora' & 'Radana' & 'Dicolor' 'Carola' \\
\hline P. pyraster 1 & 1 & & & & & \\
P. pyraster 2 & 0.3421 & 1 & & & & \\
'Conference' & 0.1842 & 0.1842 & 1 & & & \\
'Red Williams' & 0.2368 & 0.1842 & 0.3684 & 1 & 1 & 1 & \\
'Amfora' & 0.2105 & 0.1842 & 0.6842 & 0.3158 & 0.4211 & 1 \\
'Radana' & 0.2895 & 0.2632 & 0.3421 & 0.3684 & 0.2632 & 0.3684 & 1 \\
'Dicolor' & 0.2368 & 0.1842 & 0.3158 & 0.6316 & 0.4211 & 0.3947 & 0.3684 \\
'Carola' & 0.3421 & 0.2368 & 0.3421 & 0.4211 & & 1 \\
\hline
\end{tabular}

study demonstrates the usefulness of microsatellite markers for the identification of pear genotypes.

Acknowledgments This work was supported by grant N N310 305034 from the Polish Ministry of Science and Higher Education.

Open Access This article is distributed under the terms of the Creative Commons Attribution Noncommercial License which permits any noncommercial use, distribution, and reproduction in any medium, provided the original author(s) and source are credited.

\section{References}

Bao L, Chen K, Zhang D, Cao Y, Yamamoto T, Teng Y (2007) Genetic diversity and similarity of pear (Pyrus L.) cultivars native to East Asia revealed by SSR (simple sequence repeat) markers. Genet Resour Crop Evol 54:959-971

Bell RL (1986) Interspecific and intergeneric hybridization of Pyrus. Hort Sci 21(1):62-64

Browicz K (1982) Chorology of Trees and Shrubs in SouthWest Asia and adjacent regions, PWN, Warszawa-Poznań

Browicz K (1993) Conspect and chorology of the genus Pyrus L. Arbor Kórnickie 38:17-33

Castric V, Vekemans X (2004) Plant self-incompatibility in natural populations: a critical assessment of recent theoretical and empirical advances. Mol Ecol Notes 13(10):2873-2889

Dostalek J (1989) Pyrus $\times$ amphigenea, seine Taxonomie und Nomenklatur. Folia Geobot \& Phytotaxonomica 24:103-108

Fernandez-Fernandez F, Harvey NG, James CM (2006) Isolation and characterization of polymorphic microsatellite markers from European pear (Pyrus communis L.). Mol Ecol Notes 6(4):1039-1041

Gourraud PA, Barnetche T, Vidan-Jeras B, Cambon-Thomsen A (2005) Introduction to statistical analysis of population data in immunogenetics. Transpl Immunol 14(3-4):245-253

Kim H-T, Hirata Y, Nou IS (2002) Determination of S-genotypes of pear (Pyrus pyrifolia) cultivars by S-RNase sequencing and PCR-RFLP analyses. Mol Cells 3:444-451
Kim H-T, Hirata Y, Kim H-J, Nou I-S (2006) The Presence of a New S-RNase Allele (S10) in Asian Pear (Pyrus pyrifolia (Burm.) Nakai). Genet Resour Crop Evol 53(7): 1375-1383

Kutzelnigg H, Silbereisen R (1995) Pyrus. In: Hegi G (ed) Illustrierte Flora von Mitteleuropa, vol. 4. Weissadorn, Jena

Ma RC, Oliveira MM (2002) Evolutionary analysis of S-RNase genes from Rosaceae species. Mol Genet Genomics 267(1):71-78

Meusel H, Jäger E, Weinert E (1965) Vergleichende Chorologie der zentraleuropäischen Flora, 1, 1-2. Fischer, Jena

Nei M, Kumar S (2000) Molecular evolution and phylogenetics. Oxford University Press, New York

Paganova V (1996) Premenlivosť morfologických znakov kmeňa a koruny hrušky planej Pyrus pyraster (L.) Burgsd. Acta Hort et Regiotecturae 1(1):25-37

Paganova V (2001) The evaluation of height growth of wild pear (Pyrus pyraster (L) Burgsd) progenies from different regions of Slovak Republic. J For Sci 47(10):464-472

Paganova V (2003a) The lower taxa of wild pear Pyrus pyraster (L.) Burgsd. Thaiszia-J Bot

Paganova V (2003b) Wild pear Pyrus pyraster (L.) Burgsd. requirements on environmental conditions. Ekológia Bratislava 23:225-241

Paganova V (2003c) Taxonomic reliability of leaf and fruit morphological characteristics of the Pyrus L. taxa in Slovakia. Hort Sci Prague 30(3):98-107

Paganova V (2009) The occurrence and morphological characteristics of the wild pear lower taxa in Slovakia. Hort Sci (Prague) 36(1):1-13

Payne R, Murrey D, Harding S, Baird D, Soutou D, Lane P (2003) GenStat for Windows, 7 edn-Introduction. VSN International, Oxford

Rejman A (1994) Pomology - cultivars of fruit trees. PWRiL, Warsaw (in Polish)

Simpson EH (1949) Measurement of diversity. Nature 163:688

Stephan BR, Wagner I, Kleinschmit J (2003) EUFORGEN Technical Guidelines for genetic conservation and use for wild apple and pear (Malus sylvestris and Pyrus pyraster). International Plant Genetic Resources Institute, Rome 6 pages

Struss D, Plieske J (1998) The use of microsatellite markers for detection of genetic diversity in barley populations. Theor Appl Genet 97(1):308-315 
Terpo A (1985) Studies on taxonomy and grouping of Pyrus species. Feddes Repertorium 96(1-2):73-87

Terpo A, Franco J (1968) Pyrus L. In: Flora Europaea, vol. 2. Campbridge, University Press, pp 65-66

Torres AM, Weeden NF, Martín A (1993) Linkage among isozyme, RFLP and RAPD markers in Vicia faba. Theor Appl Genet 85:937-945

Weber JL, May PE (1989) Abundant class of human DNA polymorphisms which can be typed using the polymerase chain reaction. Am J Hum Genet 44(3):388-396

Yamamoto T, Kimura T, Sawamura Y, Kotobuki K, Ban Y, Hayashi T, Matsuta N (2001) SSRs isolated from apple can identify polymorphism and genetic diversity in pear. Theor Appl Genet 102:865-870

Yamamoto T, Kimura T, Sawamura Y, Manabe T, Kotobuki K, Hayashi T, Ban Y, Matsuta N (2002a) Simple sequence repeats for genetic analysis in pear. Euphytica 124:129-137
Yamamoto T, Kimura T, Shoda M, Ban Y, Hayashi T, Matsuta N (2002b) Development of microsatellite markers in the Japanese pear (Pyrus pyrifolia Nakai). Mol Ecol Notes 2:14-16

Yamamoto T, Kimura T, Shoda M, Imai T, Saito T, Sawamura Y, Kotobuki K, Hayashi T, Matsuta N (2002c) Genetic linkage maps constructed by using an interspecific cross between Japanese and European pears. Theor Appl Genet 106(1):9-18

Zisovich AH, Stern RA, Shafir S, Goldway M (2004) Identification of seven $S$-alleles from the European pear (Pyrus communis) and the determination of compatibility among cultivars. J Hortic Sci Biotech 79(1):101-106 